\title{
Effects of different heat treatments on the dynamic shear response and shear localization in Inconel 718 alloy
}

\author{
Wei-dong Song ${ }^{\mathrm{a}, *}$, Meng-lei $\mathrm{Hu}^{\mathrm{a}}$, Hu-sheng Zhang ${ }^{\mathrm{b}, *}$, Yong-xi $\mathrm{Jin}^{\mathrm{a}, \mathrm{c}}$ \\ ${ }^{a}$ State Key Laboratory of Explosion Science and Technology, Beijing Institute of Technology, Beijing 100081, PR China \\ ${ }^{\mathrm{b}}$ State Key Laboratory of Nonlinear Mechanics, Institute of Mechanics, Chinese Academy of Sciences, Beijing 100190, PR China \\ c Science and Technology on Transient Impact Laboratory, Beijing 102202, PR China
}

\section{A R T I C L E I N F O}

\section{Keywords:}

Inconel 718

Dynamic response

Adiabatic shear band

Microstructure

\begin{abstract}
A B S T R A C T
The effects of different heat treatments on the dynamic shear response and the adiabatic shear localization characteristic of Inconel 718 alloy (Inconel 718) are studied by the flat hat-shaped sample subjected to the Split Hopkinson Pressure Bar (SHPB) loading. The microstructures of the concentrated shear zone are examined by optical microscopy (OM), scanning electron microscopy (SEM), electron backscattered diffraction (EBSD), and Vickers micro-hardness tests, respectively. The results indicate that the aged Inconel 718 with higher yield strength and lower strain hardening rate is easier to form an adiabatic shear band (ASB) than that of the solution treated Inconel 718 under dynamic shear loadings. Meanwhile, it has been found that the $\delta$ phase plays an important role in inhibiting the shear localization of the solution treated Inconel 718. Little plastic deformation occurs in the region adjacent to the ASB in the aged Inconel 718, whereas significant plastic deformation occurs in a certain width area around the ASB in the solution treated Inconel 718.
\end{abstract}

\section{Introduction}

Inconel 718 is a type of widely used nickel-iron base superalloy in complex and harsh environmental conditions due to its excellent comprehensive mechanical properties such as high yield strength and remarkable creep and fatigue strengths at high temperatures [1]. It has been extensively applied to gas turbine engines, nuclear reactors, cryogenic storage tanks, and so forth. Inconel 718 is precipitation hardenable due to the presence of $\mathrm{Nb}, \mathrm{Ti}$ and $\mathrm{Al}$ in its element composition. This material is produced in different conditions depending on intended application environments. As for the aging treatment condition, the $\gamma^{\prime}$ and $\gamma^{\prime \prime}$ precipitation phases can improve the yield strength, but reduce the ductility. However, in the solution treated condition,

most of the alloying elements are dissolved in the matrix, giving the material a relatively low yield strength but high ductility. Many studies on the material property of Inconel 718 in aged condition have been done in recent years. However, differences in deformation mechanism between the solution treated condition and the aged condition attract relatively little attention.

Previous investigations on Inconel 718 mainly focus on the quasistatic deformation behaviors at elevated temperatures [2-6], and the effects of microstructures on the mechanical properties at different heat treatment conditions [7-9]. Zhang et al. [10] conducted isothermal constant speed compression tests of solution treated Inconel 718 by a computer-controlled MTS machine at temperatures from 960 to $1040{ }^{\circ} \mathrm{C}$, with original strain rates from 0.001 to $1.0 \mathrm{~s}^{-1}$. It has been found that there was an obvious power-law relationship between the flow stress and the initial strain rate. The tensile properties of forged disc of Inconel 718 have been investigated at strain rates between $10^{-4}$ and $10^{-2} \mathrm{~s}^{-1}$ and a temperature of $650^{\circ} \mathrm{C}$ by Prasad et al. [11]. They pointed out that the forged disc of Inconel 718 showed typical flow oscillations within the range of strain rates involved in the study. The dynamic compression mechanical properties of Inconel 718 at high strain rates and over wide temperature ranges were also investigated extensively. Lee et al. [12-14] evaluated the dynamic impact behaviors of Inconel 718 by SHPB tests at temperatures ranging from -150 to $550{ }^{\circ} \mathrm{C}$, and observed the microstructure evolution of Inconel 718 by using $\mathrm{OM}$ and transmission electron microscopy (TEM). The results demonstrate that the dislocation multiplication led to a strengthening effect in the plastic deformed Inconel 718, and both the flow stress and strain rate sensitivity increased with increasing the strain rate, but decreased with increasing the temperature.

As mentioned above, a wide range of material properties of Inconel 718 have been obtained through various experiments. Focusing on the material behavior during shear loading, it is necessary to understand the deformation mechanism. Kobayashi et al. [15] conducted shear

\footnotetext{
* Corresponding authors.

E-mail addresses: swdgh@bit.edu.cn (W.-d. Song), hszhang@lnm.imech.ac.cn (H.-s. Zhang).
} 
tests with a quasi-static torsion machine and a split Hopkinson torsion bar (SHTB) to investigate the plastic deformation behavior of Inconel 718 , and they also obtained the parameters for Johnson-Cook constitutive relationship by analyzing the experimental data. Shockey et al. [16] monitored the samples of Inconel 718 with a high-speed camera during the SHTB experiments and measured the time of the shear crack initiation as well as the speed of shear crack propagation in Inconel 718. Lee et al. [17] utilized the SHTB system to study the dynamic shear deformation behavior of Inconel 718 at a wide range of high shear strain rates and temperatures, and examined the fracture surfaces via $\mathrm{OM}$ and SEM. The results indicate that the temperature sensitivity of Inconel 718 declined with decreasing the strain rate and increasing the temperature. Pereira et al. [18] investigated the heat treatment effect on the ballistic impact responses and the failure mechanisms of rolled plate Inconel 718 with different annealing conditions and aged conditions. They discovered that the annealed and aged states revealed large differences not only in the yield strength, but also in the impact toughness. Demange et al. [19] conducted a series of tests to investigate the ballistic and dynamic material behaviors of Inconel 718 with the same heat treatments as mentioned by Pereira et al. [18], then developed a physical model to predict the mechanical behavior of Inconel 718 accurately. They also noted that the penetration resistance of the annealed Inconel 718 is better than that of the precipitation hardened Inconel 718. In the top hat shear tests conducted by Demange et al. [19], it is noteworthy that the precipitation hardened material readily exhibited shear localization, while the solution treated material demonstrated no evidence of shear localization. More recently, in order to understand the localization process in precipitation hardened Inconel 718, Johansson et al. [20] performed particular investigations on the microstructure of ASB formed in the precipitation hardened Inconel 718 during machining and the top hat shear tests, respectively. They compared the formed shear bands in the top-hat specimens with those generated in metal cutting chips. The observations showed the similarities between the two shear localization processes, such as the equiaxed nanocrystalline grains and the evident shear texture. Furthermore, they explored the shear localization in Inconel 718 top-hat samples with different heat treatments at a global strain rate of $1500 \mathrm{~s}^{-1}$ [21]. Both dynamic shear tests and numerical simulations have been utilized to study the effect of heat treatment condition, grain size and local geometry on shear band formation. It can be found that the aged Inconel 718 top-hat sample with small grain size and fillet radius showed the greatest tendencies for forming ASB.

As above all, the macroscopic mechanical properties of Inconel 718 have been studied widely. Typically, the solution treated Inconel 718 demonstrates stronger impact toughness than that of the precipitation hardened Inconel 718 under dynamic impact loading. The solution treated Inconel 718 can be a better candidate compared with the precipitation hardened Inconel 718 for impact energy absorption dissipation. Generally speaking, there has been little research on the shear band evolution of Inconel 718, especially the solution treated Inconel 718. Furthermore, at a microstructure level, the understanding of the differences in the shear localization of the two materials is still not clear. The goal of the present study is to characterize the dynamic shear properties and investigate the initiation and formation of ASB in Inconel 718 with two heat treatment conditions. Very high strain rate experiments $\left(8 \times 10^{4} \mathrm{~s}^{-1}\right)$ are carried out and a comprehensive study is performed to correlate the evolution of ASB to the dynamic mechanical response in the whole process of the shear localization in both the aged and solution treated Inconel 718. The microstructures in and near the shear localization regions are examined by OM, SEM and EBSD. The Vickers micro-hardness tests are performed on both of the two materials to analyze the effects of different heat treatments on the shear localization.

\section{Materials and experimental procedures}

The Inconel 718 bars used in the present investigation are purchased from Thyssen Krupp VDM USA Ltd. The chemical composition is $18.47 \% \mathrm{Cr}, 17.22 \% \mathrm{Fe}, 5.30 \% \mathrm{Nb}, 3.14 \% \mathrm{Mo}, 0.96 \% \mathrm{Ti}, 0.57 \% \mathrm{Al}$, $0.22 \% \mathrm{Co}, 0.01 \% \mathrm{Si}, 0.08 \% \mathrm{Mn}, 0.05 \% \mathrm{Cu}, 0.03 \% \mathrm{C}, 0.003 \% \mathrm{~B}$, and a balance of $\mathrm{Ni}$ (all in wt\%). The raw materials are in wrought as rods of $24 \mathrm{~mm}$ and $45 \mathrm{~mm}$ diameters, respectively. The $24 \mathrm{~mm}$ rods are heat treated through the standard commercial procedure. To be specific, the solution treated is at $954^{\circ} \mathrm{C}$ for $1 \mathrm{~h}$ and subjected to water quenching to room temperature and then aging treated is at $720^{\circ} \mathrm{C}+/-5^{\circ} \mathrm{C}$ for $8 \mathrm{~h}$, furnace cooling at the rate of $50^{\circ} \mathrm{C} / \mathrm{h}$ to $620^{\circ} \mathrm{C}+/-5^{\circ} \mathrm{C}$, holding at this temperature for $8 \mathrm{~h}$, and finally cooling by forced air to room temperature. The $45 \mathrm{~mm}$ rods are merely solution treated. The Inconel 718 bars for dynamic shear experiments are machined into flat hatshaped samples by wire saw with loading direction parallel to the axis of rods. The both ends of each sample are then carefully polished by waterproof abrasive paper of 800 meshes to guarantee a close contact with the incident and transmission bars during the SHPB tests. The configuration of the flat hat-shaped sample for SHPB experiments is shown in Fig. 1(a), and the geometric size of the flat hat-shaped specimen is also given in Fig. 1(b). The flat hat-shaped specimen is designed to concentrate shear deformation in a narrow area. This similar design of the specimen is also used to study ASB in various metal materials [22-26].

A schematic of the SHPB test configuration is shown in Fig. 2. The designed flat hat-shaped specimen is sandwiched between the incident and transmission bars. The impact bar is launched from a gas gun a predetermined velocity towards the incident bar. Upon impact on the A head face, a compressive pulse is generated in the incident bar and travels towards the specimen. The pulse duration is equal to the round trip travel time of the longitudinal wave in the impact bar. Upon reaching the specimen, a portion of the incident pulse is transmitted into the transmission bar as a compression pulse, and the rest of portion is reflected back into the incident bar traveling toward the impact end, A. The strain gages are bonded at midpoints along the length of the incident and transmission bars in order to capture the stress pulse as it passes by. Based on the one-dimensional elastic stress wave theory and considering the design form of flat hat-shaped sample, the shear stress, the shear displacement, the nominal shear strain and the nominal shear strain rate can be calculated by following formulas:

$$
\begin{aligned}
& \tau=E\left(\frac{A_{b}}{A_{s}}\right) \varepsilon_{T} \\
& U=2 C_{0} \int_{0}^{t}\left(\varepsilon_{I}-\varepsilon_{T}\right) d t \\
& \gamma=U / l_{s} \\
& \dot{\gamma}=\frac{2 C_{0}}{l_{s}}\left(\varepsilon_{I}-\varepsilon_{T}\right) \\
& l_{s}=\frac{A B-C D}{2} \\
& A_{s}=2 h d \\
& A_{b}=\frac{\pi d_{0}^{2}}{4}
\end{aligned}
$$

where $\varepsilon_{I}$ and $\varepsilon_{T}$ are the incident and transmitted strain pulses, which can be obtained by the strain gages bonded on the bars, respectively. $E, C_{0}$ and $A_{b}$ are the Young's modulus, the stress wave velocity and the crosssectional area of the loading bars, respectively. $\tau, U, \gamma$ and $\dot{\gamma}$ are the shear stress, the shear displacement, the nominal shear strain and the 


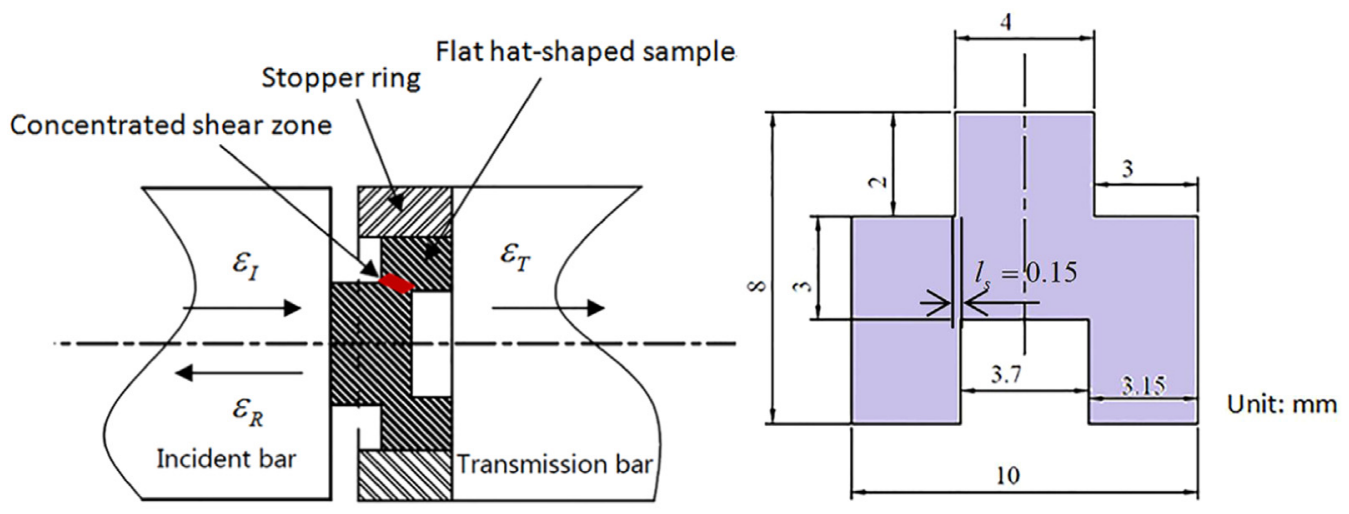

(a)

(b)

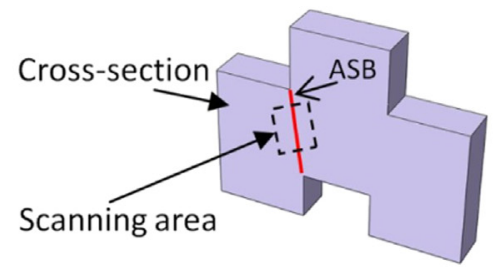

(c)

Fig. 1. (a) Schematic of the specimen sandwiched between bars; (b) geometric shape and dimensions of flat hat-shaped specimen; (c) sample sketch cut in longitudinal for microstructure observations.

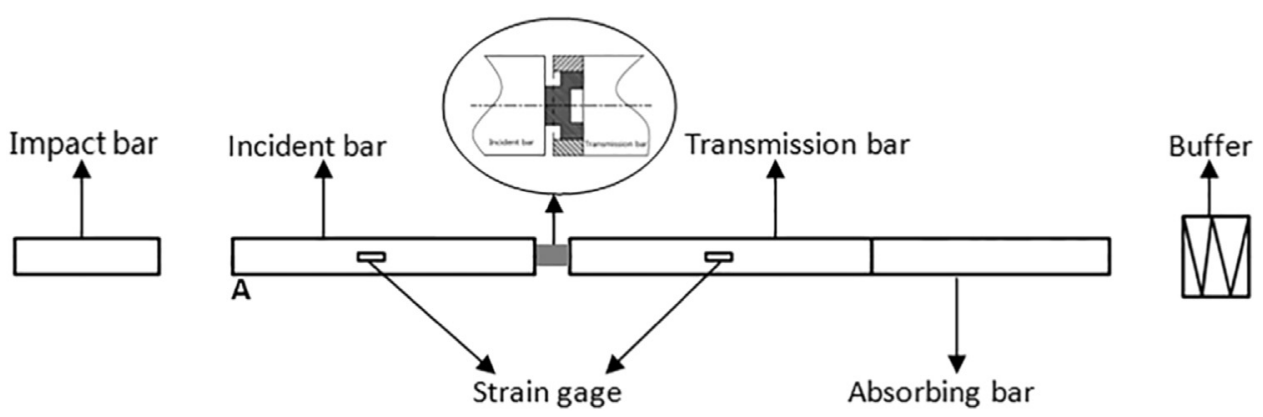

Fig. 2. The schematic of the SHPB test configuration.

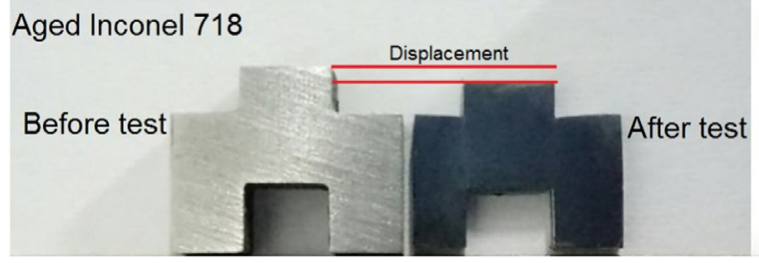

(a)
Solution treated Inconel 718

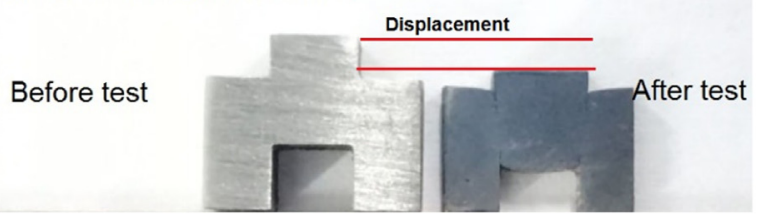

(b)

Fig. 3. Samples for the dynamic shear tests (a) aged Inconel 718; (b) solution treated Inconel 718; left before test, right after test in each picture.

nominal shear strain rate, respectively. $l_{s}$ is the width of shear zone and $A_{s}$ is the area of the concentrated shear zone. $t$ is the wave propagation time. $\mathrm{AB}=4 \mathrm{~mm}, \mathrm{CD}=3.7 \mathrm{~mm}$. $\mathrm{h}$ is the height of shear zone and $\mathrm{d}$ is the thickness of the sample. $d_{0}$ is the diameter of SHPB.

The same impact bar ( $300 \mathrm{~mm}$ in length) is used during the whole tests to maintain a constant loading pulse width. The diameter of SHPB is $13 \mathrm{~mm}$ and the thickness of flat hat-shaped sample is $3 \mathrm{~mm}$. The stopper rings in different thicknesses $(7.8 \mathrm{~mm}, 7.64 \mathrm{~mm}, 7.52 \mathrm{~mm}$ and $7.48 \mathrm{~mm}$ for the aged Inconel $718 ; 7.64 \mathrm{~mm}, 7.31 \mathrm{~mm}, 6.94 \mathrm{~mm}$ and $6.85 \mathrm{~mm}$ for the solution treated Inconel 718) are applied to control the shear displacements of the specimens. All the flat hat-shaped samples are tested at room temperature and a global strain rate of $8 \times 10^{4} \mathrm{~s}^{-1}$, and are then cut in half along the longitudinal direction after the tests. The half section of the specimens are inlaid on epoxy resin and ground progressively by using a series of abrasive papers with grit sizes ranging from 200 to 5000 mesh afterwards. The grinded specimens are then polished with $0.5 \mu \mathrm{m}$ polishing paste and $0.25 \mu \mathrm{m}$ finally. After completion of polishing, the specimens are etched with $1.5 \mathrm{~g} \mathrm{CuSO}_{4}$ $+20 \mathrm{ml} \mathrm{HCl}+20 \mathrm{ml} \mathrm{C}_{2} \mathrm{H}_{5} \mathrm{OH}$ for approximately $4 \mathrm{~min}$. The surface morphologies, especially the concentrated shear zone of the impacted 


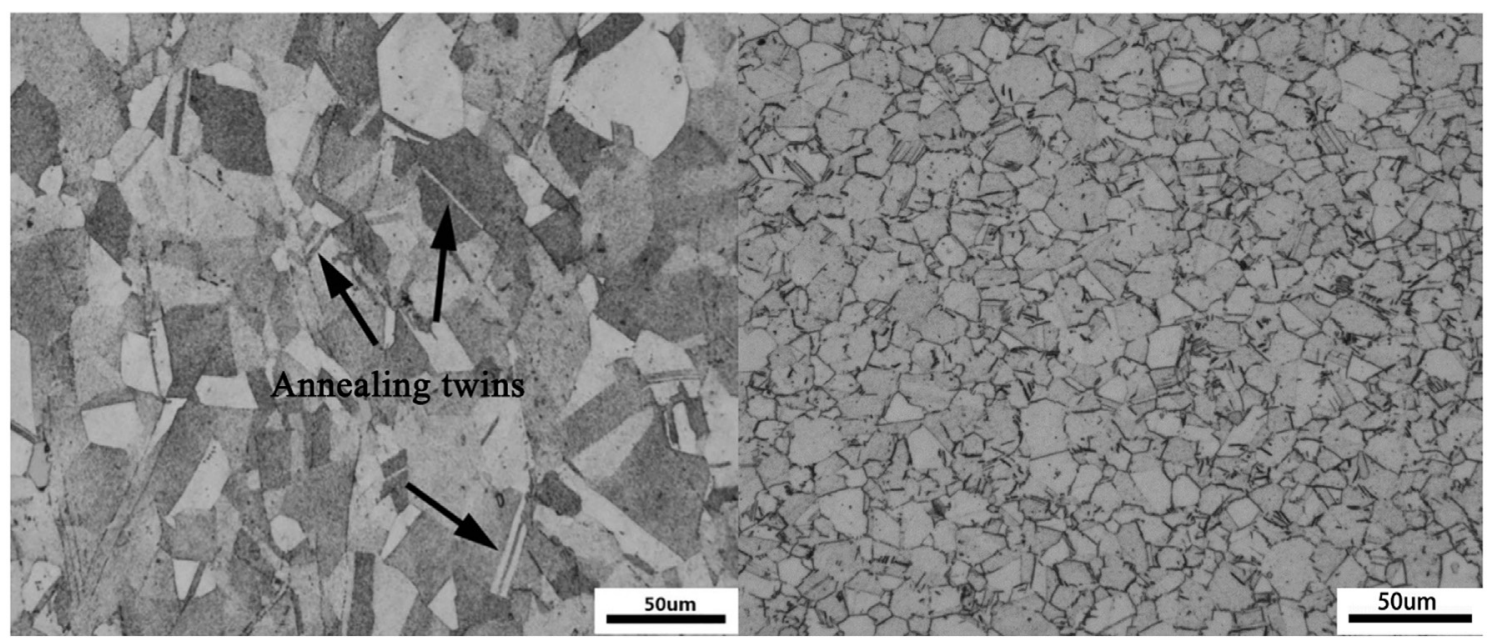

(a)

(b)

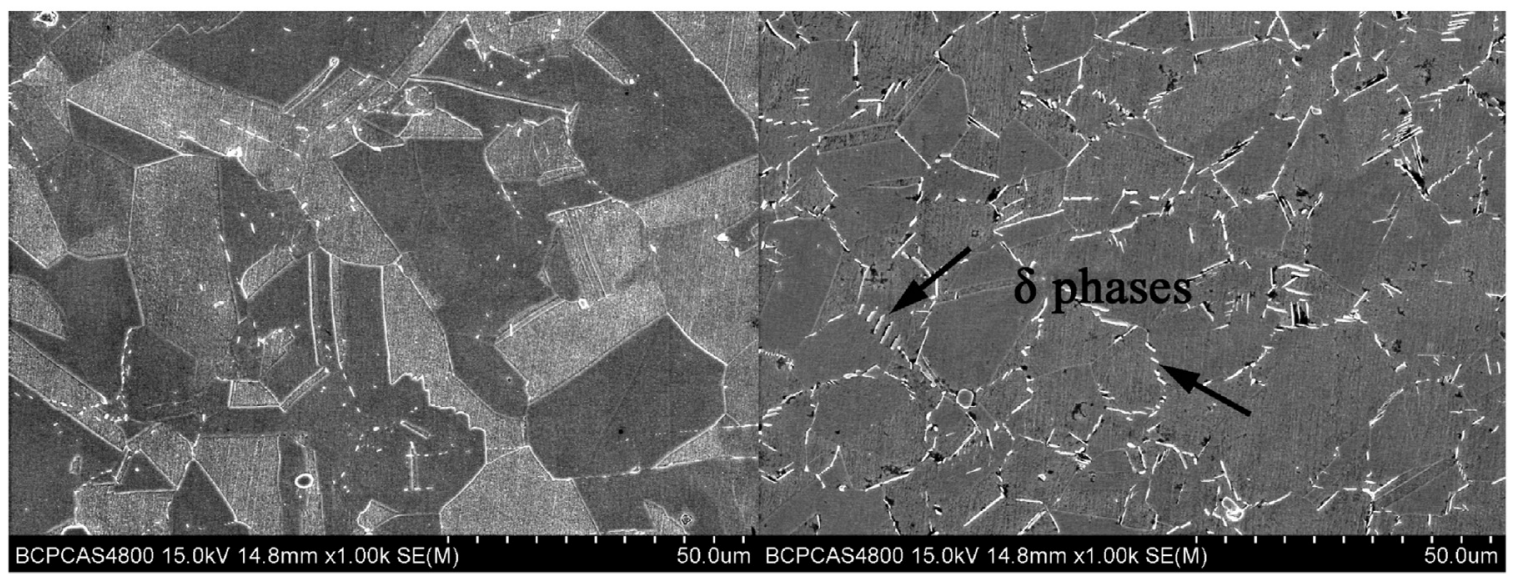

(c)

(d)

Fig. 4. Microstructure of Inconel 718; (a) OM image, the aged condition; (b) OM image, the solution treated condition; (c) SEM micrograph, the aged condition; (d) SEM micrograph, the solution treated condition.

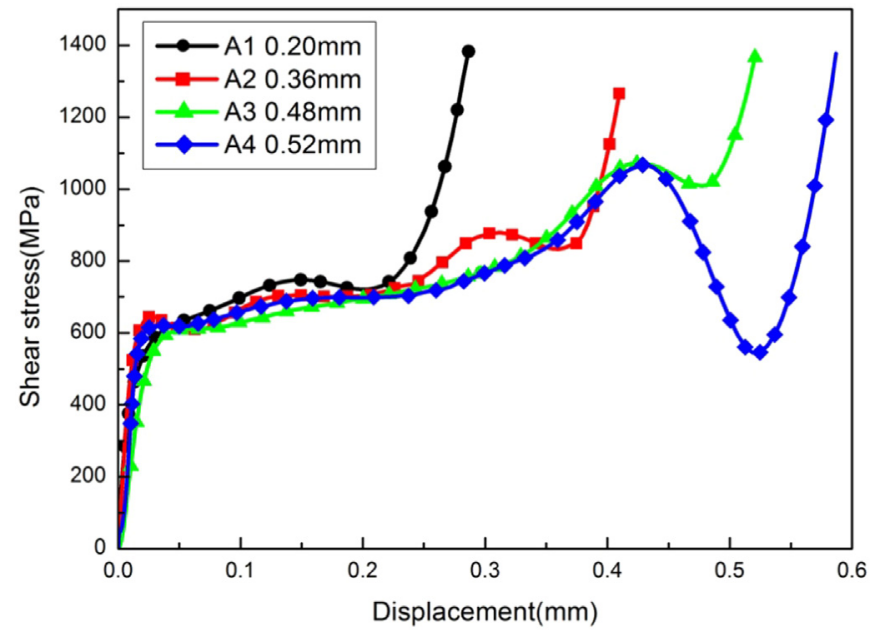

Fig. 5. Shear stress vs. shear displacement curves of Inconel 718 in aged condition.

specimens are then examined by OM and SEM. A diagram in Fig. 1(c) intuitively shows the rough area needed to be observed. Since the quality of EBSD sample surface has great effect on the accuracy and precision of testing results, the mechanical polished half section of specimens are then electro polished to remove the surface residual stress and reveal the microstructure for EBSD. The Vickers microhardness tests are performed on the Inconel 718 flat hat-shaped samples before and after the shear experiments. A Vickers hardness pyramid indenter is employed under a load of $5 \mathrm{~g}$ for a dwelling time of fifteen seconds. Three groups of measurements across the ASB for each specimen are recorded, and the mean value is calculated in order to reduce the measurement error. The samples of Inconel 718 before and after the experiments are displayed in Fig. 3(a) and (b). The right sample in each picture has been cut in half by wire cutting and electro-polished in preparation for metallographic analysis. When the ASB just formed, the shear displacement in Fig. 3(a) is much smaller than that of in Fig. 3(b). Under the same loading conditions, the ASB forms more easily in the aged Inconel 718 than that of the solution treated Inconel 718.

\section{Experimental results and discussion}

\subsection{Microstructure with different heat treatments}

The metallographic structures of Inconel 718 in aged condition and solution treated condition observed by OM and SEM are shown in Fig. 4, respectively. As shown in Fig. 4(a), the grains of Inconel 718 in aged condition are equiaxed crystals with an average grain size of about $28 \mu \mathrm{m}$ and are mainly characterized by $\gamma$ matrix phase. Multiple phases exist in the aged Inconel 718, but the particles are too small to be seen 


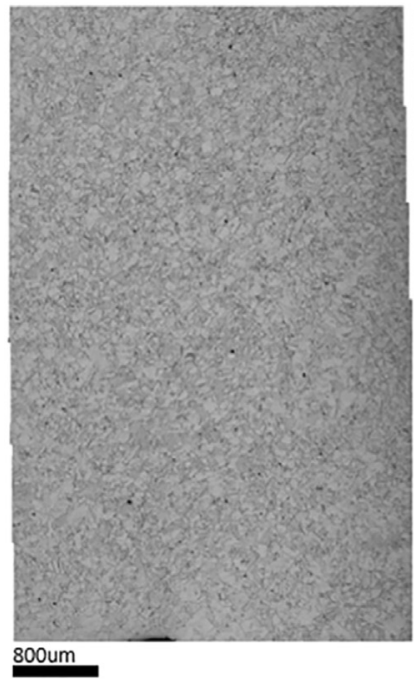

(a)

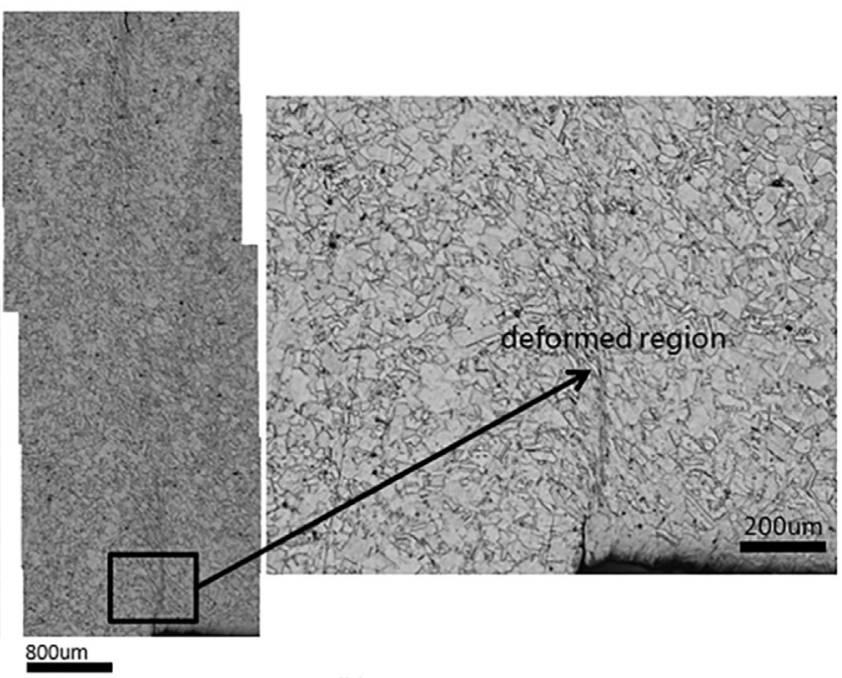

(b)

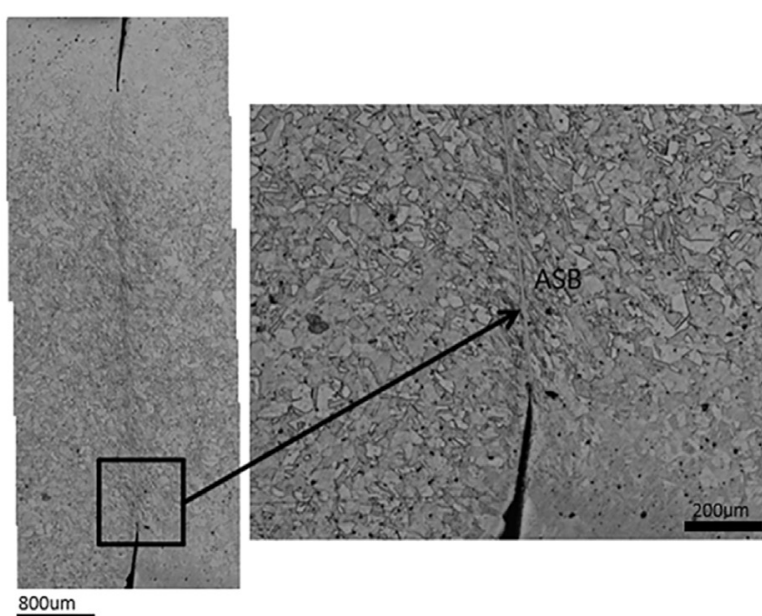

(c)

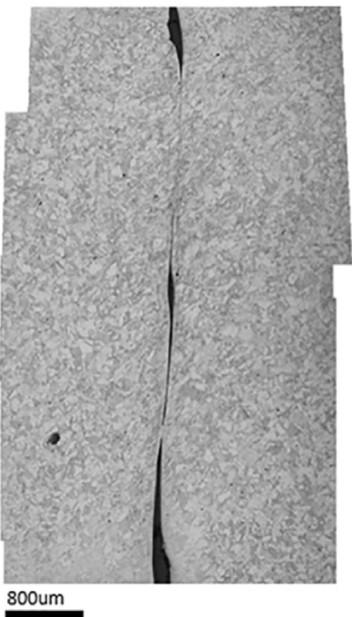

(d)

Fig. 6. Evolution of localized deformation in aged Inconel 718 at different shear displacements: (a) A1 $=0.20$ mm, small deformation, no shear band; (b) A2 $=0.36 \mathrm{~mm}$, evident deformation but no shear band; (c) A3 $=0.48 \mathrm{~mm}$, more deformed and a shear band completely formed; (d) A4 $=0.52 \mathrm{~mm}$, crack nucleation and growth.

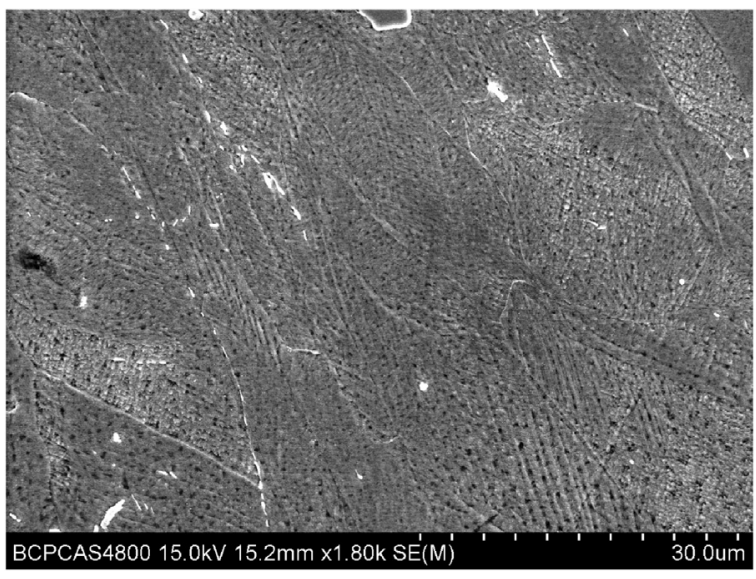

Fig. 7. SEM micrograph of the shear zone in aged Inconel 718 at $0.36 \mathrm{~mm}$ displacement.

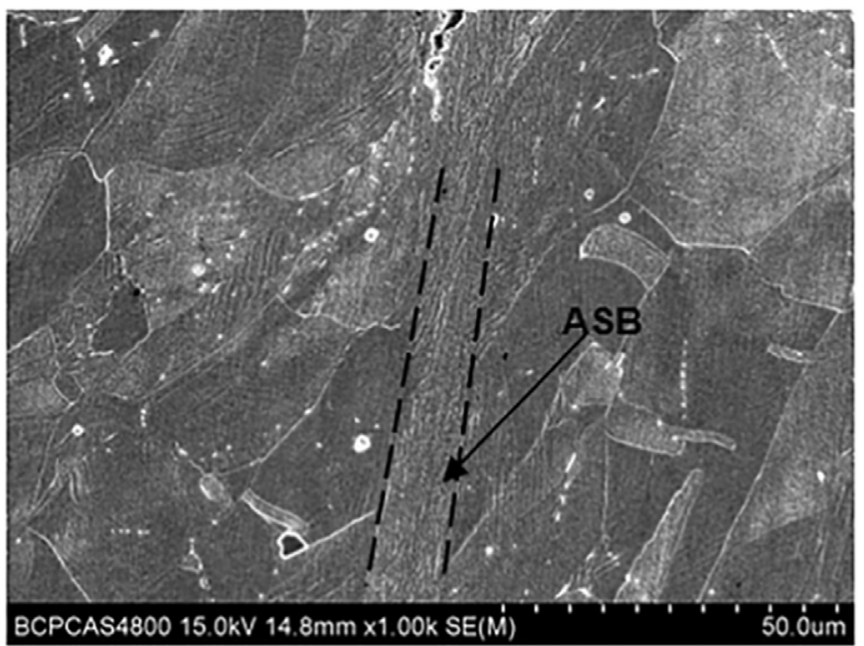

Fig. 8. SEM micrograph of the shear zone in aged Inconel 718 at $0.48 \mathrm{~mm}$ displacement. 


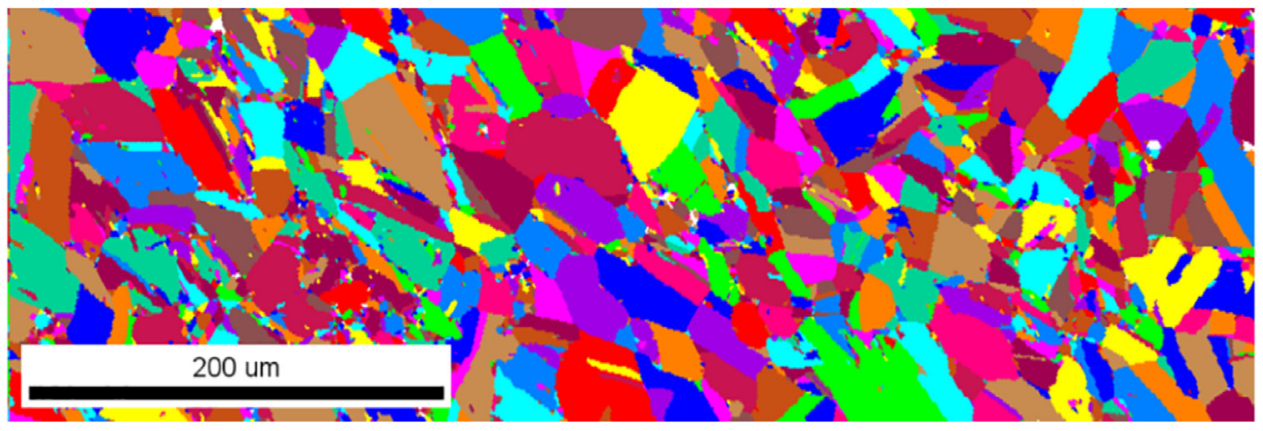

(a)

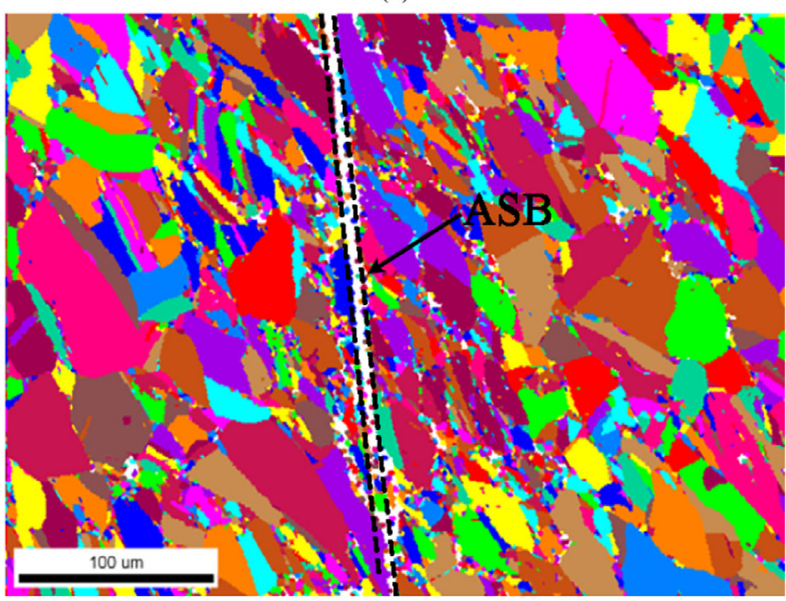

(b)

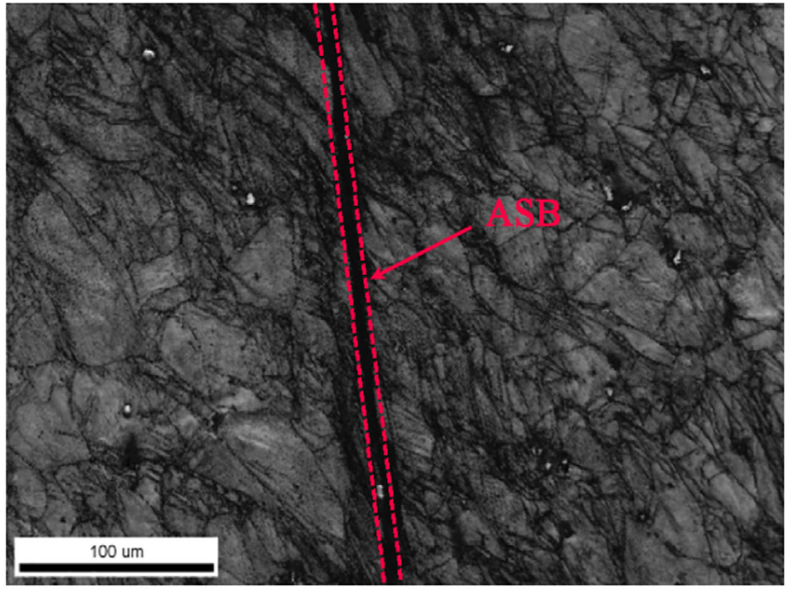

(c)

Fig. 9. The grain distribution maps by EBSD at two different interrupted displacements for the aged Inconel 718: (a) $0.36 \mathrm{~mm}$; (b) $0.48 \mathrm{~mm}$. (c) Band contrast map corresponding to (b).

at this scale from Fig. 4(a)-(d). Many studies mentioned above have reported the elements composition of these phases, such as the $\gamma^{\prime}$ $\left(\mathrm{Ni}_{3} \mathrm{Al}, \mathrm{Ti}\right)$ and $\gamma^{\prime \prime}\left(\mathrm{Ni}_{3} \mathrm{Nb}\right)$ phase. Both the $\gamma^{\prime}$ phase and $\gamma^{\prime \prime}$ phase are strengthening precipitates of the aged Inconel 718, especially the $\gamma^{\prime \prime}$ phase. Some lamella-like straight annealing twins are marked with black arrows in Fig. 4(a). In Fig. 4(b), the equiaxed crystals are also observed in the solution treated Inconel 718 but with an average grain size of about $18 \mu \mathrm{m}$. Most of the alloy elements in Inconel 718 are dissolved in the matrix during the solution heat treatment, so there is almost no discrete strengthening phase in the solution treated Inconel 718. The needle like $\delta$ phase marked with arrows in Fig. 4(d) are pinned on the grain boundaries, thus suppressing the grain growth and reducing the grain size [21]. The $\delta$ phase in the solution treated Inconel 718 could improve the impact toughness as well as the plasticity. Moreover, the $\delta$ phase can also prevent the void on the grain boundary from joining into the crystalline boundary crack and then reduces the crack growth rate.

\subsection{Evolution of ASB under dynamic shear loading}

\subsubsection{Formation of ASB in aged Inconel 718}

The interrupted tests are carried out to explore the formation and evolution mechanisms of ASB in the aged Inconel 718 by SHPB apparatus. By way of adjusting the stopper ring's thickness, as displayed in Fig. 1(a), the loading process is controlled and sequentially the shear deformation process is interrupted at four different stages. The shear deformation process of the aged Inconel 718 under dynamic shear loadings at a strain rate of about $8 \times 10^{4} \mathrm{~s}^{-1}$ is shown in Fig. 5. A1-A4 


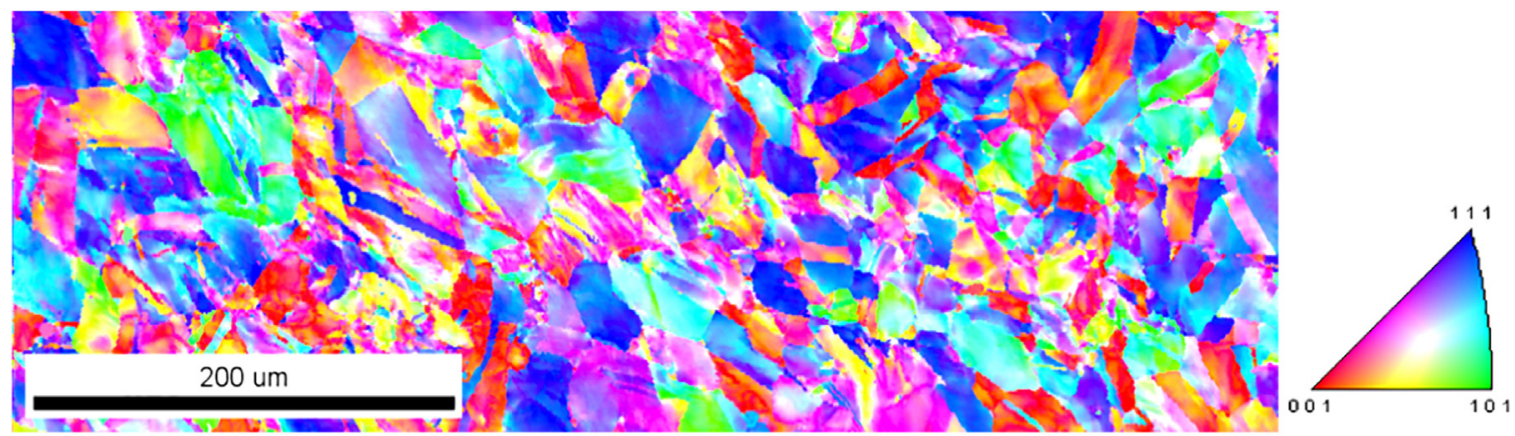

(a)

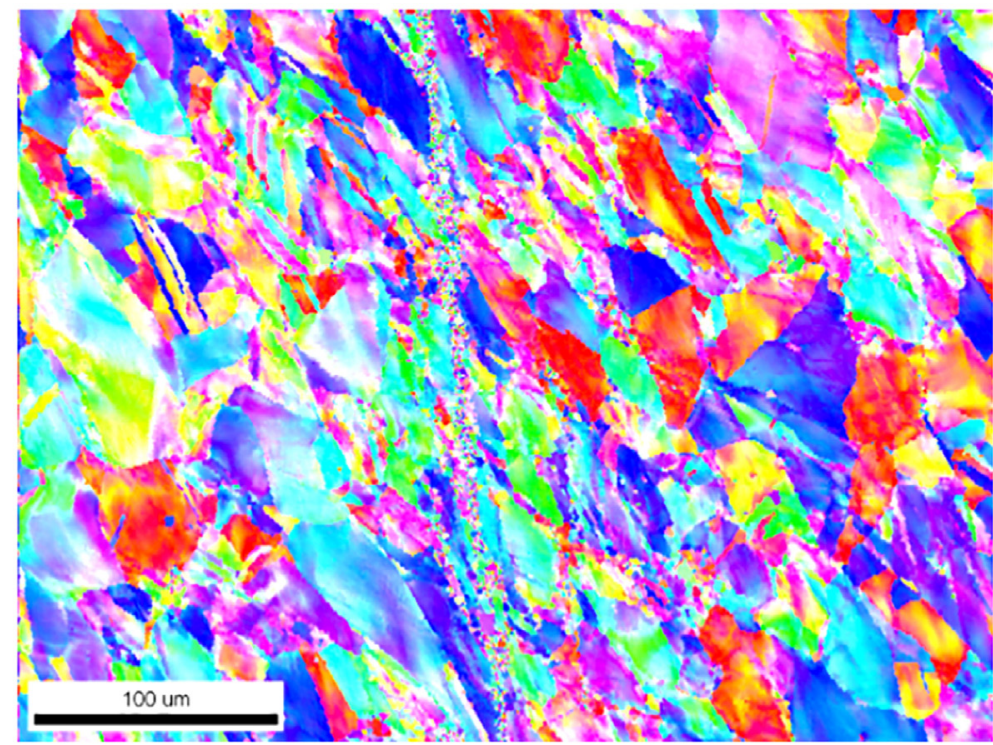

(b)

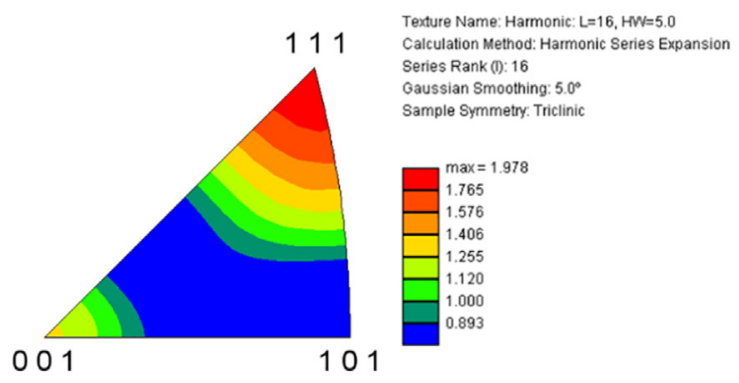

(c)

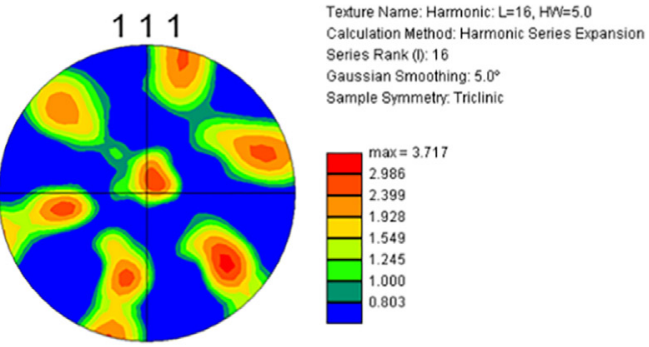

(d)

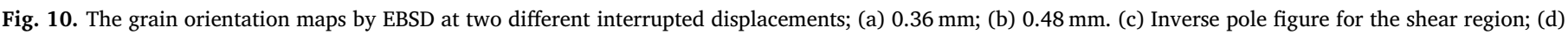
texture corresponding to the grain orientation map shown in (b).

curves represent the mechanical behavior correlated to a certain loading duration on the samples, respectively. At the ends of A1-A4 curves, the shear stresses rise sharply when the incident bar hits the stopper ring. This is because the stopper ring has a much higher yield strength than the aged Inconel 718 sample. In Fig. 5, the aged Inconel 718 shows a strain hardening behavior under the dynamic shear loading conditions.

The interrupted tests have the advantage of quantitative ability to correlate the dynamic mechanical response to the evolution of the microstructure of Inconel 718. The corresponding metallographic structures of the aged Inconel 718 at four different deformation stages are shown in Fig. 6(a)-(d). It should be noted that in Fig. 6 the top of the picture is the hat end of the flat hat-shaped sample, and the bottom of the picture is the base end of the sample. According to the A1 curve in Fig. 5 and the corresponding OM micrograph in Fig. 6(a), no local deformation occurs in the sample when the shear displacement reaches $0.20 \mathrm{~mm}$. At the A2 displacement stage $(0.36 \mathrm{~mm})$, it can be observed that there are some evident plastic deformed areas in both ends of the sample, but the magnified OM micrograph of the black box region shows no ASB development. The close observation of the severely deformed shear region in the specimen at $0.36 \mathrm{~mm}$ displacement is also displayed in Fig. 7, which indicates a high density of slip bands and also illustrates that the plastic deformation is insufficient to generate an ASB. When the shear displacement increases to $0.48 \mathrm{~mm}$, an obvious 


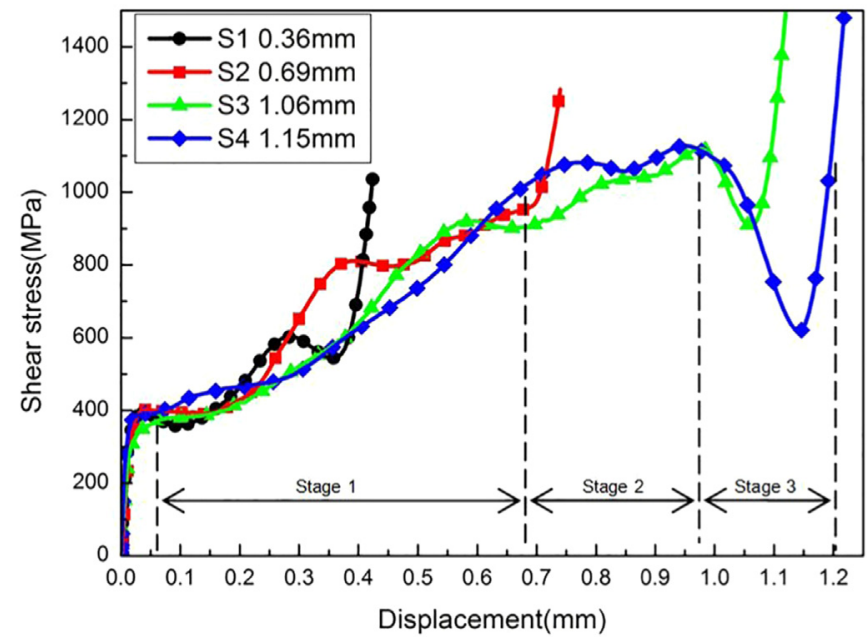

Fig. 11. Shear stress vs. shear displacement curves of Inconel 718 in solution treated condition.

shear band appears in the concentrated shear region of the aged Inconel 718 sample (see Fig. 6(c)). The shear band width is estimated to be about $10 \mu \mathrm{m}$ by the SEM micrograph, see Fig. 8. Additionally, Fig. 8 also shows that the grains adjacent to the shear band are just slightly elongated and rotated. The shear band in the aged Inconel 718 can be clearly distinguished from the surrounding area. Before the initiation of the ASB, the deformation of the concentrated shear zone can be assumed to be homogeneous. The nominal shear strain in the flat hatshaped sample can be estimated by dividing the shear displacement by the width of the concentrated shear area. The critical shear strain for the initiation of the shear localization is between 2.4 and 3.2. As shown in Fig. 6(d), cracks along the shear band of the specimen can be clearly seen when the shear displacement is up to $0.52 \mathrm{~mm}$. In accordance with Fig. 6(d), the sudden decline of A4 curve in Fig. 5 is a macroscopic reflection of the shear localization and crack nucleation.

Grain distributions and orientations across to the shear zone of the samples are characterized by EBSD. A step size of $1 \mu \mathrm{m}$ is chosen in order to optimize the resolution without increasing too much acquisition time, because a high resolution can cause a high sensitivity to drift. Both the Figs. 9(a) and 10(a) indicate that the grains in the concentrated shear zone are deformed uniformly and there is no formation of the shear band, which is in agreement with the OM micrograph in Fig. 6(b). The white band (un-indexed pixels) in Fig. 9(b) is determined to be the shear band in the aged Inconel 718 samples and matches well

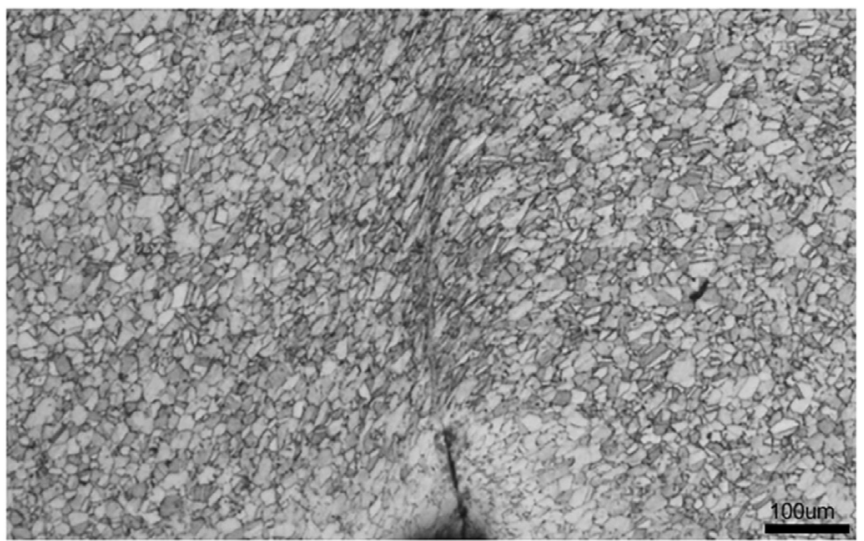

Fig. 13. Shear band formed in the sample at displacement of $0.69 \mathrm{~mm}$. Note that this area is selected from the dashed black box in Fig. 10(b).

with the OM micrographs. The region of the grain orientation distribution shown in Fig. 10(b) is consistent with the region shown in Fig. 9(b). The corresponding pole figure of (111) indicating a distinct shear texture is also demonstrated in Fig. 10(d). The inserted triangle in Fig. 10(a) is the legend to the grain orientation map, in which grains having [001, 101] and [111] directions parallel to the direction of cross-section are in red, green and blue, respectively. The inverse pole figure in Fig. 10(c) indicates that the slip plane is (111). It is worth mentioning that the small grains appearing in the shear band edges and the shear bands in Figs. 9(b) and 10(b) are the result of inaccurate data removal during EBSD data processing. Normally, there are evident transition layers in the vicinity of the shear bands [27-29]. However, the transition layers do not exist in the aged Inconel 718 samples. The transition from uniform shear deformation area to the shear band is very sharp, which can be observed in Fig. 9(b). The abrupt transition is also displayed in the band contrast map of the same region in Fig. 9(c). Similar observations are also found by Johansson et al. [20]. The band contrast is sensitive to the presence of the high and low angle grain boundaries and thus can be used to characterize the microstructure of the Inconel 718 alloy.

\subsubsection{Evolution of ASB in solution treated Inconel 718}

The solution treated Inconel 718 specimens are tested at a strain rate of $7.9 \times 10^{4} \mathrm{~s}^{-1}$ and the shear stress vs. the shear displacement curves are shown in Fig. 11. The roughly equivalent loading conditions are applied to guarantee the similar nominal shear strain rates for both

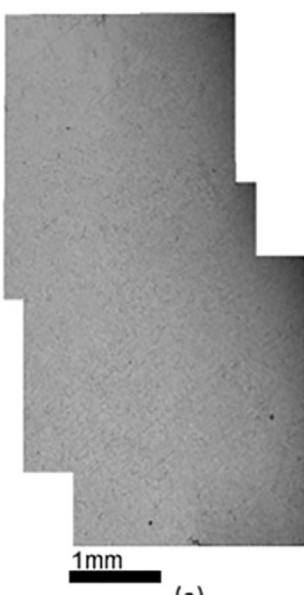

(a)

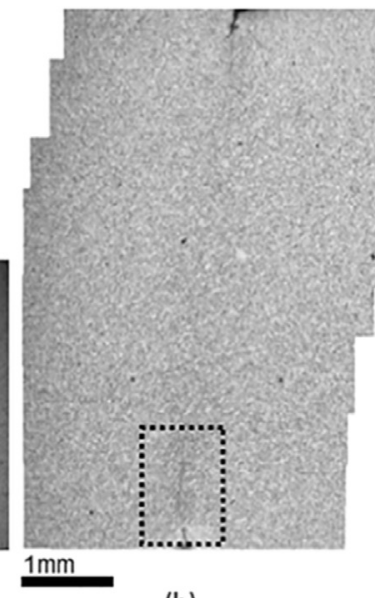

(b)

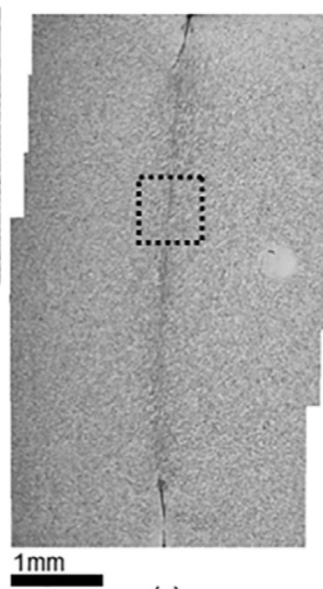

(c)

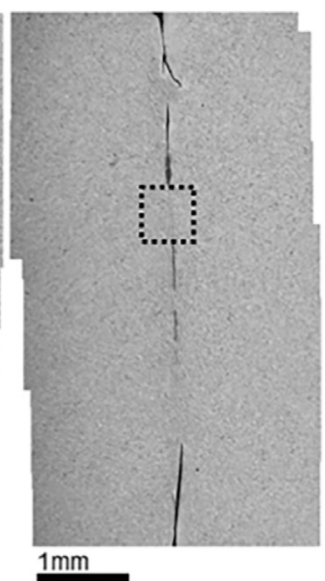

(d)

Fig. 12. Evolution of localized deformation in solution treated Inconel 718 at different shear displacements; (a) $\mathrm{S} 1=0.36 \mathrm{~mm}$, homogeneous deformation; (b) $\mathrm{S} 2=0.69 \mathrm{~mm}$, ASB initiation; (c) S4 $=1.06 \mathrm{~mm}$, ASB formed completely; (d) S5 = $1.15 \mathrm{~mm}$ cracks nucleation and propagation. 


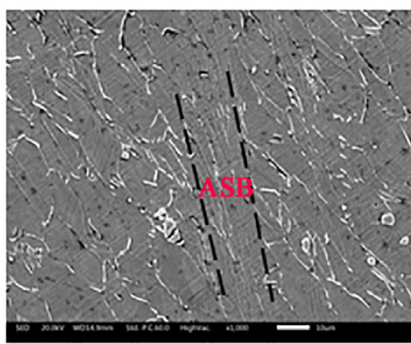

(a)

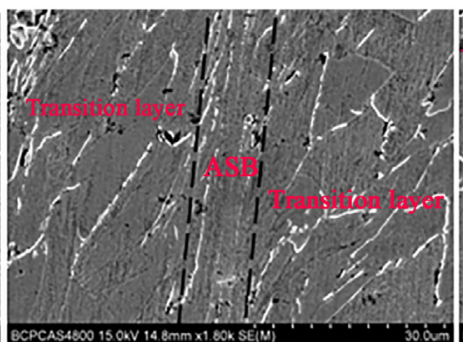

(b)

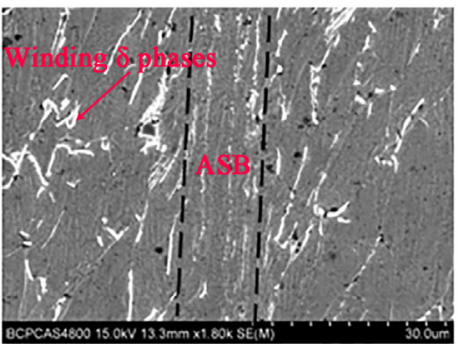

(c)

Fig. 14. SEM micrographs of the ASB at three different displacements; (a) black box area in Fig. 10(b), $0.69 \mathrm{~mm}$; (b) black box area in Fig. 10 (c), $1.06 \mathrm{~mm}$; (c) black box area in Fig. 10(d), $1.15 \mathrm{~mm}$.

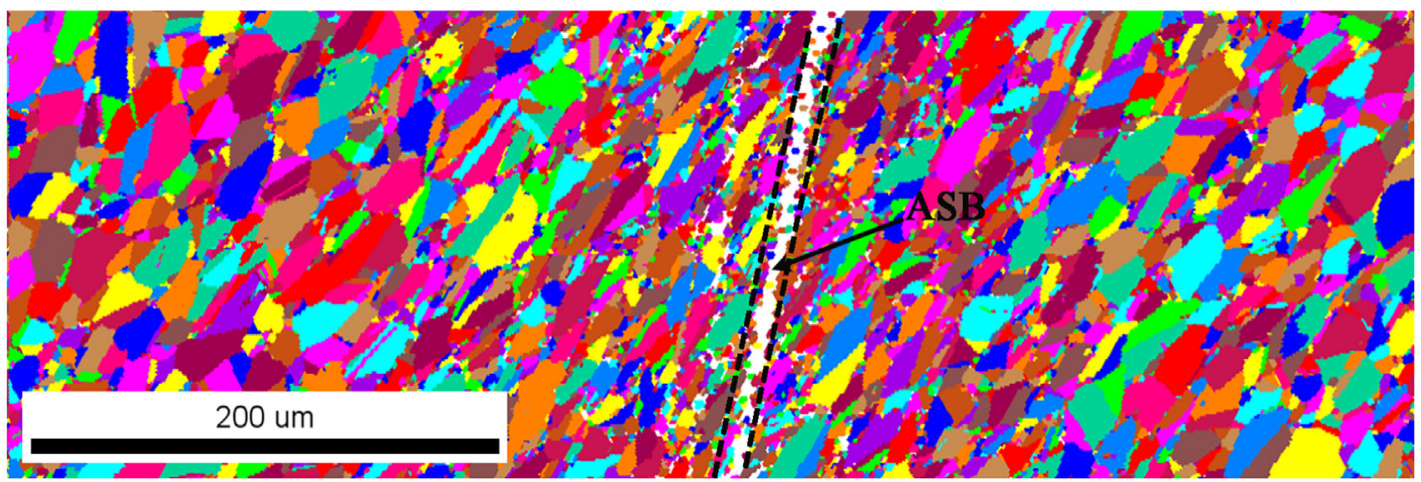

(a)

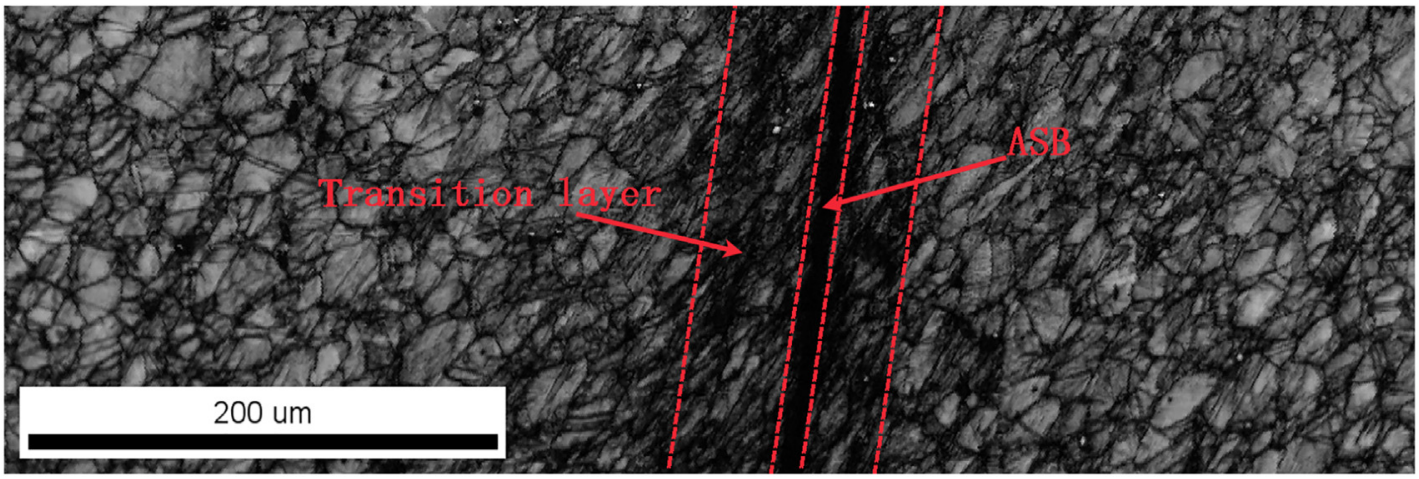

(b)

Fig. 15. EBSD maps at a displacement of $1.06 \mathrm{~mm}$. (a) Grain distribution map; (b) band contrast map.

the aged and the solution treated specimens. S1-S4 curves represent the dynamic shear responses of the solution treated Inconel 718 at four different shear displacements, respectively. These shear stress curves display a yield strength ranging from 380 to $410 \mathrm{MPa}$, which is lower than that of the aged Inconel 718. The plastic deformation process of the sample can be roughly divided into three stages. At the first stage, before the shear displacements reach $0.68 \mathrm{~mm}, \mathrm{~S} 1$ and S2 curves exhibit an evident strain hardening. At the second stage, the thermal softening effect weakens the strain hardening effect and makes S3 and S4 curves rise gently to the peak stress of about $1160 \mathrm{MPa}$. At the third stage, the shear stress drops abruptly after the displacement of $0.97 \mathrm{~mm}$ and then rises sharply when the incident bar hits the stopper ring.

The OM photographs in Fig. 12 corresponding to the four stress curves show a sequential development of the shear localization in the solution treated Inconel 718 samples. According to formula (3), the critical shear strain before the ASB initiation is approximately 4.5. Fig. 12(a) shows the uniform deformation of the microstructure prior to the formation of the shear band. Fig. 13 displays an obvious shear band, which is marked by a black box in Fig. 12(b). According to Figs. 12(b) and 13 , it can be roughly estimated that a shear band initiates on the top of the specimen before the shear displacement reaches $0.69 \mathrm{~mm}$. Compared with the aged Inconel 718, the solution treated Inconel 718 displays a considerably more deformation in the region adjacent to the shear band. In Fig. 12(b), (c) and (d), the shear band regions marked by black boxes are examined by SEM and then the SEM micrographs are shown in Fig. 14(a)-(c), respectively. There is a trend toward an increase in shear band width with increasing the shear displacement. According to the scale labels in the micrographs, the widths of the three shear bands are measured to be about $10-13 \mu \mathrm{m}$, which are a little wider than that of the shear bands in the aged Inconel 718. By carefully observing the needle-like $\delta$ phases in the transition layers shown in Fig. 14(a), (b) and (c), it is found that they are elongated, rotated and even bent with the increase of shear displacement. It can be observed from S3, S4 curves and the microstructures shown in Fig. 12(c) and (d) that cracks nucleation occurs between the displacement of $1.06 \mathrm{~mm}$ and $1.15 \mathrm{~mm}$. The load drop does not occur until the shear band forms 


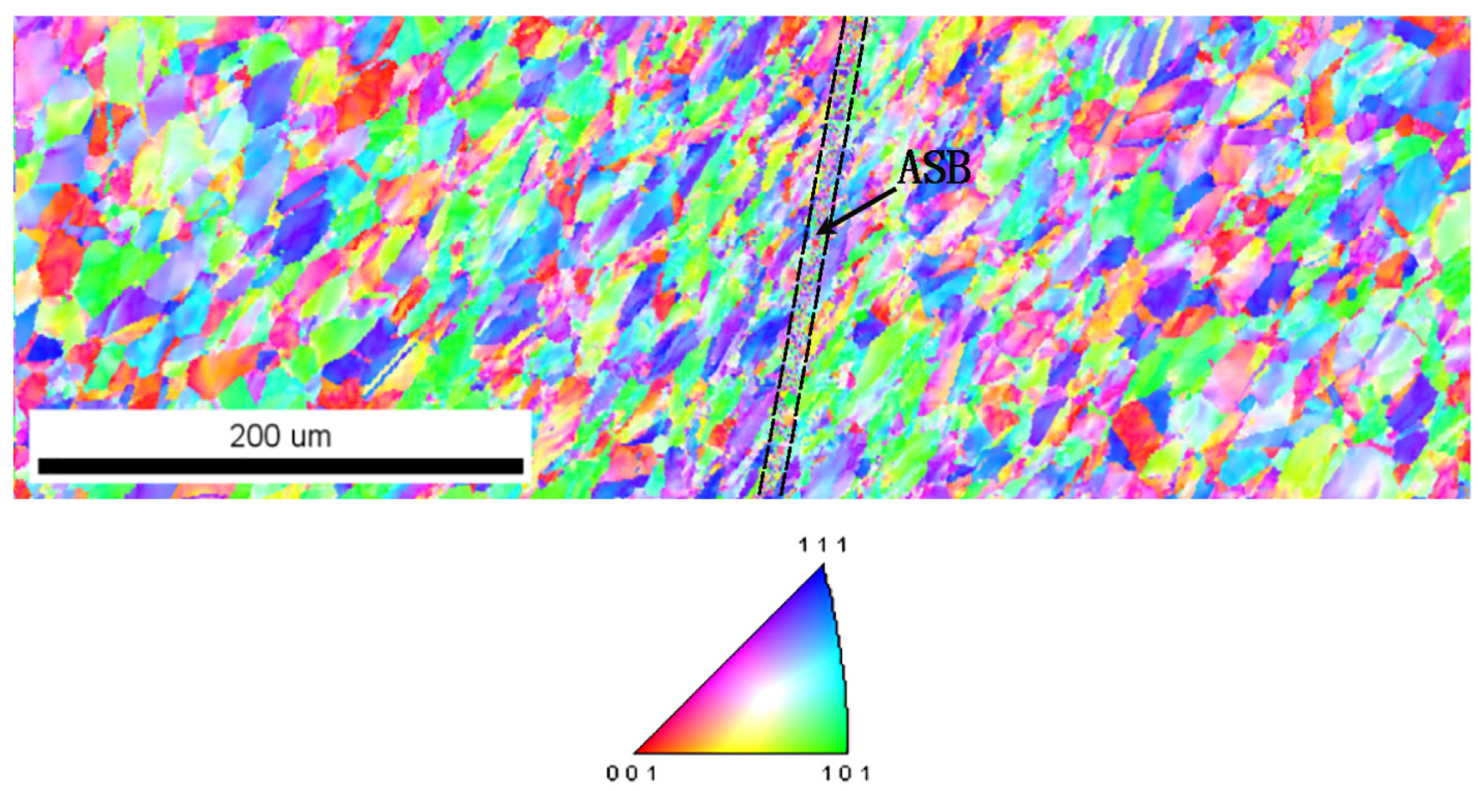

(a)

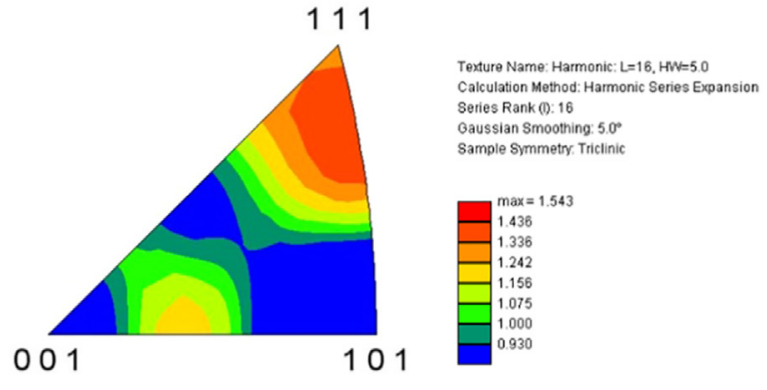

(b)

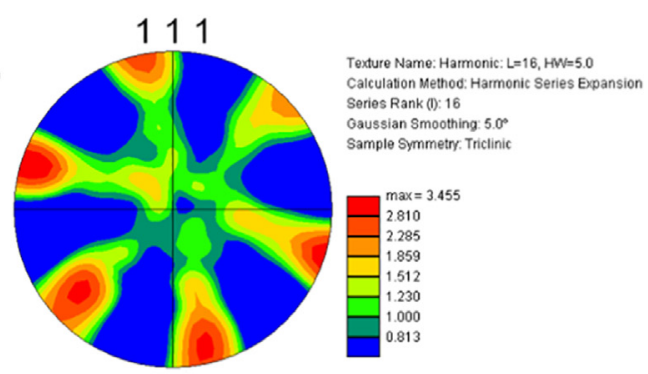

(c)

Fig. 16. (a) Grain orientation map of solution treated Inconel 718 at a displacement of $1.06 \mathrm{~mm}$; (b) inverse pole figure for the shear region; (c) distinct shear texture corresponding to the grain orientation map shown in (a).

completely in the solution treated Inconel 718.

The grain distribution map at a shear displacement of $1.06 \mathrm{~mm}$ and the corresponding band contrast map are shown in Fig. 15(a) and (b), respectively. In Fig. 15(a), the grains are represented by different colors except for the white area. The white band with a poor Kikuchi pattern quality is just the area where the shear band appears. A large shear deformation will cause a poor Kikuchi pattern quality, especially in the shear band. Fig. 16(a) plots the grain orientation map at a shear displacement of $1.06 \mathrm{~mm}$. The grains of the solution treated Inconel 718 in a certain region around the shear band have been seriously elongated and rotated, which can be easily observed from the band contrast map in Fig. 15(b). The deformed region is a transition layer and is marked with red dashed lines in Fig. 15(b), which is quite different from that of the aged Inconel 718. Moreover, the inverse pole figure (Fig. 16(b)) and pole figure of (111) (Fig. 16(c)) are obtained by EBSD mapping analysis. The (111) pole figure indicates a distinct shear texture and the inverse pole figure in Fig. 16(b) shows that the primary slip plane is (111).

\subsubsection{Distribution of micro-hardness}

The Vickers microhardness tests on the surface of Inconel 718 samples are performed before and after the dynamic shear tests. The mean Vickers microhardness values and standard deviation for the Inconel 718 samples before shear tests are plotted in Fig. 17(a). Fig. 17(b) exhibits the Vickers micro-hardness distributions of the adiabatic shear bands and the surrounding areas at different interrupted shear displacements. As demonstrated in Fig. 17(b), the ASB in both the aged and the solution treated Inconel 718 is found to have the highest microhardness. The initial hardness for the aged Inconel 718 is higher than that of the solution treated Inconel 718. After shear tests, the concentrated shear zones in the solution treated samples are subjected to a more severe plastic deformation than that of the aged samples. This phenomenon can be identified by comparing the microstructures in Figs. 9 and 15. The severe plastic deformation in the concentrated shear zone will lead to a much higher dislocation density in the solution treated Inconel 718 than that in the aged Inconel 718. All this leads to a much higher microhardness of the solution treated Inconel 718 than that of the aged Inconel 718, see Fig. 17(b). The hardness of the shear band increases with the shear displacement, which is more obvious in the aged Inconel 718. However, in the vicinity of the ASB in the aged Inconel 718 samples, the microhardness values are almost equal to the initial hardness, which also verifies that the deformation adjacent to the ASB is very small. It is proved that the formation of the ASB in the aged Inconel 718 does not cause a significant increase in the dislocation density in the surrounding areas. However, in the ballistic impact experiments conducted by Pereira et al. [18], it has been found that the hardness values of the aged Inconel 718 were higher in all locations than that of the solution treated Inconel 718, due to the fact that the material was originally aged. 


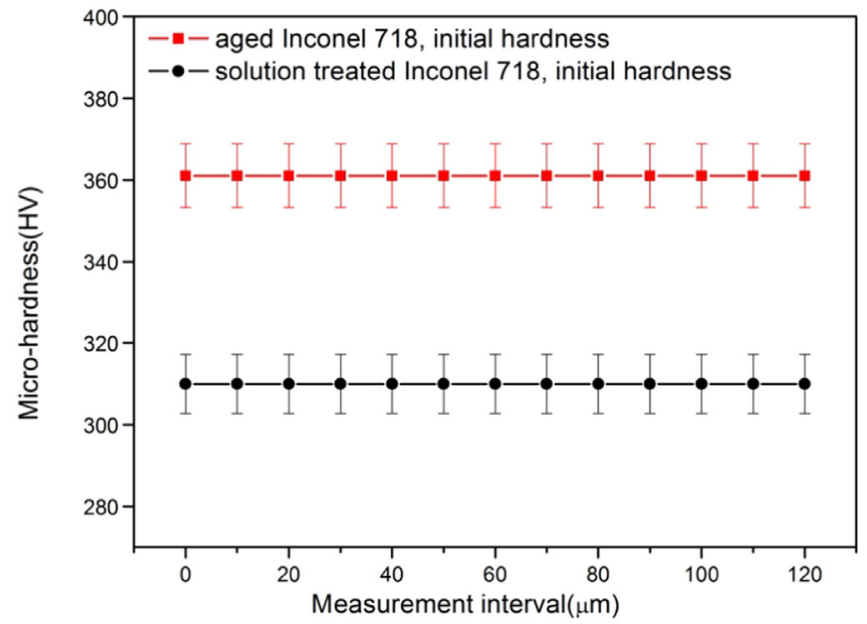

(a)

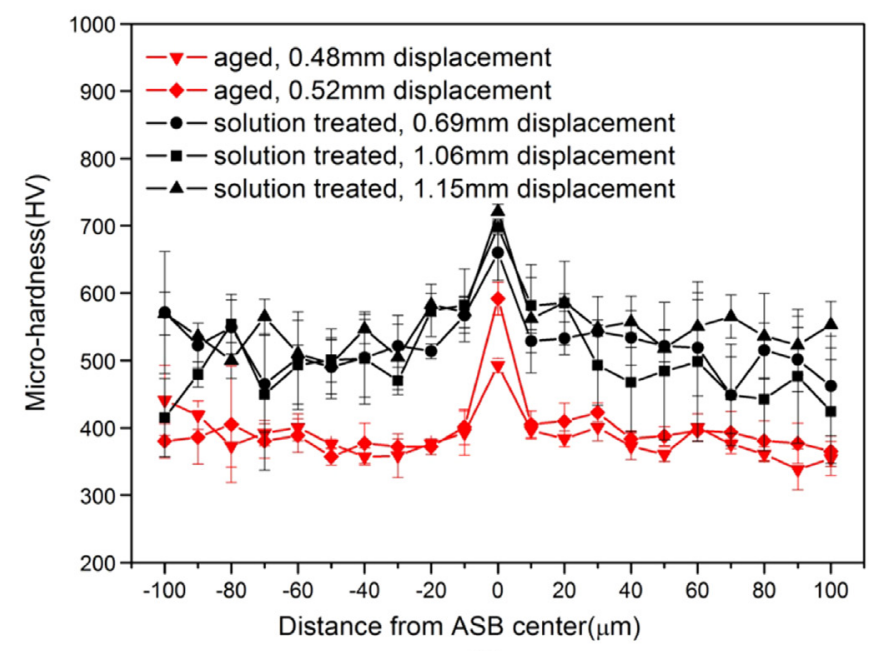

(b)

Fig. 17. (a) The Vickers microhardness before shear tests; (b) the Vickers microhardness distributions traversing the shear zones.

\subsection{Discussion}

According to the EBSD maps illustrated in Figs. 15 and 16 and the SEM micrographs displayed in Fig. 14, the plastic deformation area adjacent to the ASB in the solution treated Inconel 718 is heavily deformed. In contrast, the aged Inconel 718 does not exhibit a severe plastic deformation in the area around the ASB. The main difference between the aged and the solution treated samples is the deformation regions adjacent to the adiabatic shear bands. The solution treated Inconel 718 sample accommodates substantial plastic deformations and a high density of dislocations, while the aged sample displays a small plastic deformation. The $\delta$ phase plays an important role in suppressing shear localization. The solution treated Inconel 718 does not contain precipitation strengthening phase but a lot of $\delta$ phases pinned on grain boundaries. The existing $\delta$ phases will lead to an evident strain hardening, thus can dominate thermal softening and subsequently inhibit the initiation and formation of the ASB. During the dynamic shear process, it is difficult for the grains of the solution treated Inconel 718 to slip due to strain hardening effect. In this condition, the deformation region spreads to neighboring grains, which dissipates the input energy [19]. The difference in the shear localization between the aged Inconel 718 and the solution treated Inconel 718 is also reflected in their dynamic shear responses. Although the shear yield stress in the solution treated Inconel 718 sample is much lower than that in the aged Inconel 718 sample, its peak stress is almost equal to its aged counterpart. The solution treated Inconel 718 displays more distinct strain hardening than that of the aged Inconel 718. The shear localization at the base end of the flat hat-shaped sample initiates earlier than the hat ends, and the similar phenomenon has been reported in previous studies [21,25]. It can be seen from the shape of the Inconel 718 sample that the base end has less constraint to the shear deformation than that of the hat end. In the shearing process, the hat end is difficult to deform due to a big compressive stress. Therefore the shear band is easier to appear at the base end of the Inconel 718 sample. The measurements and calculation results, such as the shear strength, the nominal shear strain rate and the average misorientation angles of the grain orientation maps are summarized in Table 1.

The local misorientation can be used to characterize the changes of the grain orientation in the metal plastic deformation [30,31]. The average value of local misorientation increases with the increase of the material deformation, which can be used as a quantitative index of dislocation density [32]. In the present study, misorientation angle shows the distribution of grain boundary misorientations over the whole region which has been scanned by EBSD. The original data acquired by EBSD has been processed by OIM analysis software. The measured and averaged regions are in accordance with Figs. 10(a) and (b) and 16(a). The average misorientation angle is obtained by calculating the weighted average value of the misorientation angle. By comparing the average misorientation angle in Table 1, it is also found that the dislocation density of the solution treated Inconel 718 is higher than that of the aged Inconel 718.

The maximum stress criterion [24-26] illustrates that the peak shear stress is usually regarded as the initiation point of strain localization, after which the material deformation begins to localize into a shear band. However, some different experiment results are obtained in the present study. The ASB initiates in the solution treated sample at the interrupted displacement of $0.69 \mathrm{~mm}$ (Fig. 12(b)), but the corresponding S2 stress curve neither reaches the peak point nor suddenly drops down. It is worth noting that the shear localization may occur before the stress peaks. Johansson [21] et al. compared the dynamic mechanical properties of Inconel 718 with the results of a metallographic examination from the dynamic shear tests. They suggested that the load drop may be delayed by the formation of the ASB and does not occur until the ASB is completely formed. However, they also found that in some conditions there were well developed adiabatic shear bands in the tests, while no load drop was observed. In the process of ASB evolution in Ti-6Al-4V alloy [33], when the material flow stress reaches the maximum, the material is still in the stage of uniform deformation, and no localized deformation occurs. This indicates that the maximum stress criterion as the shear band formation criterion is

Table 1

Comparison of experimental results.

\begin{tabular}{|c|c|c|c|c|c|c|}
\hline \multirow[b]{2}{*}{ Interrupted Displacement (mm) } & \multicolumn{3}{|c|}{ Aged Inconel 718} & \multicolumn{3}{|c|}{ Solution treated Inconel 718} \\
\hline & 0.36 & 0.48 & 0.52 & 0.69 & 1.06 & 1.15 \\
\hline Yield strength (MPa) & 650 & 620 & 610 & 410 & 380 & 400 \\
\hline Peak strength (MPa) & N/A & 1100 & 1100 & 1070 & 1070 & 1070 \\
\hline Nominal shear strain rate $\left(\mathrm{s}^{-1}\right)$ & $8 \times 10^{4}$ & $8 \times 10^{4}$ & $8 \times 10^{4}$ & $7.9 \times 10^{4}$ & $7.9 \times 10^{4}$ & $7.9 \times 10^{4}$ \\
\hline Average misorientation angle & 12.58 & 13.60 & $\mathrm{~N} / \mathrm{A}$ & N/A & 17.22 & N/A \\
\hline
\end{tabular}


limited. In fact, the shear strain in the shear band obtained by the experimental measurements is tens or even more than the average strain of the material, and the strain rate in the shear band is several orders of magnitude higher than the average strain rate required for its formation [34], which indicates that the formation of the shear band is also related to the strain rate.

\section{Conclusions}

The dynamic shear responses and adiabatic shear localization in both the aged and solution treated Inconel 718 alloy are investigated in the interrupted SHPB experiments. The post-observation of the metallographic structures offered the insight into the shear deformation behavior at the microscopic level. The conclusions are drawn as below:

1. The $\delta$ phase plays an important role in inhibiting the shear localization of the solution treated Inconel 718 to improve the impact toughness as well as the plasticity, thus resulting in a higher strain hardening rate.

2. Less shear deformation in the matrix adjacent to the ASB can be observed in the aged Inconel 718 after dynamic shear loading, while a significant plastic deformation occurs in a certain width area around the ASB in the solution treated one.

3. Vickers microhardness in the shear band increases with shear displacement. It is note worthy that the Vickers microhardness of the concentrated shear regions in the solution treated Inconel 718 is much higher than that of the aged one.

\section{Acknowledgments}

The authors acknowledge the financial support of the National Natural Science Foundation of China (11672043 and 11521062), the National Key R\&D Program of China (2016YFC0801200), the Opening Project of State Key Laboratory of Traction Power (TPL1701), the project of Science and Technology on Transient Impact Laboratory (614260601010617) and other projects of China (6140922020116BQ01002 and SAST2017-029).

\section{References}

[1] T.S. Byun, K. Farrell, Tensile properties of Inconel 718 after low temperature neutron irradiation, J. Nucl. Mater. 318 (2003) 292-299.

[2] Y. Wang, W.Z. Shao, L. Zhen, L. Yang, X.M. Zhang, Flow behavior and microstructures of superalloy 718 during high temperature deformation, Mater. Sci. Eng. A 497 (2008) 479-486.

[3] L.X. Zhou, T.N. Baker, Effects on dynamic and metadynamic recrystallization on microstructures of wrought IN-718 due to hot deformation, Mater. Sci. Eng. A 196 (1995) 89-95.

[4] J.M. Zhang, Z.Y. Gao, J.Y. Zhuang, Z.Y. Zhong, Modeling of grain size in superalloy IN718 during hot deformation, J. Mater. Process. Technol. 88 (1999) 244-250.

[5] Y. Wang, W.Z. Shao, L. Zhen, X.M. Zhang, Microstructure evolution during dynamic recrystallization of hot deformed superalloy 718, Mater. Sci. Eng. A 486 (2008) 321-332.

[6] M. Urdanpilleta, J.M. Martinez-Esnaola, J.G. Sevillano, Strain rate sensitivity of superplastic Inconel 718, Mater. Trans. 46 (2005) 1711-1719.

[7] H. Yuan, W.C. Liu, Effect of the $\delta$ phase on the hot deformation behavior of Inconel 718, Mater. Sci. Eng. A 408 (2005) 281-289.
[8] S. Sui, J. Chen, E. Fan, H. Yang, X. Lin, W. Huang, The influence of Laves phases on the high-cycle fatigue behavior of laser additive manufactured Inconel 718, Mater. Sci. Eng. A 695 (2017) 6-13.

[9] Y.H. Kong, R.Y. Liu, G.S. Chen, L.X. Xie, S.G. Zhu, Effects of different heat treatments on the microstructures and creep properties of GH4169 superalloy, J. Mater. Eng. Perform. 22 (2013) 1371-1377.

[10] J.M. Zhang, Z.Y. Gao, J.Y. Zhuang, Z.Y. Zhong, P. Janschek, Strain-rate hardening behavior of superalloy IN718, J. Mater. Process. Technol. 70 (1997) 252-257.

[11] K. Prasad, R. Sarkar, P. Ghosal, V. Kumar, Tensile deformation behaviour of forged disc of IN 718 superalloy at $650{ }^{\circ} \mathrm{C}$, Mater. Des. 31 (2010) 4502-4507.

[12] W.S. Lee, C.F. Lin, T.H. Chen, H.W. Chen, Dynamic impact response of Inconel 718 alloy under low and high temperatures, Mater. Trans. 52 (2011) 1734-1740.

[13] W.S. Lee, C.F. Lin, T.H. Chen, H.W. Chen, Dynamic mechanical behaviour and dislocation substructure evolution of Inconel 718 over wide temperature range, Mater. Sci. Eng. A 528 (2011) 6279-6286.

[14] W.S. Lee, C.F. Lin, T.H. Chen, H.W. Chen, Retracted: effects of temperature and strain rate on deformation behaviour of Inconel 718 alloy, Mater. Chem. Phys. 129 (2011) 832-839.

[15] T. Kobayashi, J.W. Simons, C.S. Brown, D.A. Shockey, Plastic flow behavior of Inconel 718 under dynamic shear loads, Int. J. Impact Eng. 35 (2008) 389-396.

[16] D.A. Shockey, J.W. Simons, C.S. Brown, T. Kobayashi, Shear failure of Inconel 718 under dynamic loads, Exp. Mech. 47 (2007) 723-732.

[17] L. Woeishyan, C.F. Lin, T.H. Chen, C.S. Huang, Dynamic shear properties of Alloy 718 over wide temperature range, Mater. Trans. 53 (2012) 1758-1764.

[18] J.M. Pereira, B.A. Lerch, Effects of heat treatment on the ballistic impact properties of Inconel 718 for jet engine fan containment applications, Int. J. Impact Eng. 25 (2001) 715-733.

[19] J.J. Demange, V. Prakash, J.M. Pereira, Effects of material microstructure on blunt projectile penetration of a nickel-based super alloy, Int. J. Impact Eng. 36 (2009) 1027-1043.

[20] J. Johansson, C. Persson, H. Lai, M.H. Colliander, Microstructural examination of shear localisation during high strain rate deformation of Alloy 718, Mater. Sci. Eng. A 662 (2016) 363-372.

[21] J. Johansson, C. Persson, G. Testa, A. Ruggiero, N. Bonora, M.H. Colliander, Effect of microstructure on dynamic shear localisation in Alloy 718, Mech. Mater. 109 (2017) 88-100.

[22] M.A. Meyers, Y.B. Xu, Q. Xue, M.T. Pérez-Prado, T.R. McNelley, Microstructural evolution in adiabatic shear localization in stainless steel, Acta Mater. 51 (2003) 1307-1325.

[23] M.T. Pérez-Prado, J.A. Hines, K.S. Vecchio, Microstructural evolution in adiabatic shear bands in Ta and Ta-W alloys, Acta Mater. 49 (2001) 2905-2917.

[24] M.A. Meyers, G. Subhash, B.K. Kad, L. Prasad, Evolution of microstructure and shear-band formation in $\alpha$-hcp titanium, Mech. Mater. 17 (1994) 175-193.

[25] Q. Xue, G.T. Gray, B.L. Henrie, S.A. Maloy, S.R. Chen, Influence of shock prestraining on the formation of shear localization in 304 stainless steel, Metall. Mater. Trans. A 36 (2005) 1471-1486.

[26] A. Mishra, M. Martin, N.N. Thadhani, B. Kad, M.A. Meyers, High-strain rate response of ultra-fine grained copper: experiments and analysis, Acta Mater. 56 (2008) 2770-2783.

[27] J.F.C. Lins, H.R.Z. Sandim, K.S. Vecchio, D. Raabe, An EBSD investigation on deformation-induced shear bands in Ti-bearing IF-steel under controlled shockloading conditions, Mater. Sci. Forum 495-497 (2005) 393-398.

[28] F. Yuan, X. Bian, P. Jiang, M. Yang, X. Wu, Dynamic shear response and evolution mechanisms of adiabatic shear band in an ultrafine-grained austenite-ferrite duplex steel, Mech. Mater. 89 (2015) 47-58.

[29] F. Yuan, P. Jiang, X. Wu, Annealing effect on the evolution of adiabatic shear band under dynamic shear loading in ultra-fine-grained iron, Int. J. Impact Eng. 50 (2012) 1-8.

[30] F.J. Humphreys, P.S. Bate, P.J. Hurley, Orientation averaging of electron backscattered diffraction data, J. Microsc. 201 (2001) 50-58.

[31] A. Godfrey, Edge preservation near triple junctions during orientation averaging of EBSP data, Scr. Mater. 50 (2004) 1097-1101.

[32] Y. Meng, Q. Ren, X.H. Ju, Evaluation of dislocation density by local grain misorientation in deformed metals, Trans. Mater. Heat Treat. 35 (2014) 122-128.

[33] Y. Bai, Q. Xuc, Y. Xu, L. Shen, Characteristics and microstructure in the evolution of shear localization in Ti-6Al-4V alloy, Mech. Mater. 17 (1994) 155-164.

[34] Y. Xu, Y. Bai, Shear localization, microstructure evolution and fracture under highstrain rate, Adv. Mech. 37 (2007) 496-516. 